\title{
Wolfgang Blankenburg - Qual é o alcance da abordagem dialética na psiquiatria?
}

\section{Wolfgang Blankenburg - What is the scope of the dialectical approach in psychiatry?}

\author{
Tradução de Paula Alves Martins de Araújo ${ }^{1}$, Revisão técnica: Guilherme Messas ${ }^{2}$
}

Os esclarecimentos que seguem não reivindicam responder suficientemente essa pergunta. Elas gostariam apenas de a formular de modo mais categórico e, ao mesmo tempo, mais concisamente, para assim abrir o caminho para possíveis soluções. Deve-se ter em conta que, no quadro das investigações fenomenológicas, predomina uma outra relação entre a formulação de um problema e sua solução, diferente daquela que ocorre na maior parte das demais disciplinas científicas. Salientar e aprofundar uma pergunta significa aqui já um passo essencial para sua resposta.

Para poder delimitar e precisar a pergunta, faz-se necessário primeiro elucidar o que se deve ter em vista com o termo "dialético". O conceito tem atrás de si uma longa e movimentada história e está sobrecarregado por uma série de equívocos. O seu significado passou por diversas mudanças desde a Antiguidade $^{3}$. No Dicionário histórico de filosofia (Ritter, 1972, vol. 2, col. 164 a 226), lançado por J. Ritter, uma dúzia de autores se dedicaram a traçar a história do conceito comprimida ao essencial. O mesmo aconteceu em uma série de compêndios e revisões bibliográficas ${ }^{4}$. Aqui não trataremos desse desenvolvimento, revestido por algumas contradições. É suficiente esboçar brevemente o que entendemos pela palavra "dialética" (dialektisch) nas presentes investigações. Prontamente, esta se deixa caracterizar como uma certa relação com o negativo enquanto tal. Mais precisamente: é a hipótese de trabalho sobre uma possível positividade do negativo, tomada como orientação heurística, e não mais do que isso. A hipótese de trabalho pode se manter ou não. Seria melhor, em virtude da quantidade de significados disparatados com que a palavra "dialética" foi e é guarnecida, achar um termo menos carregado para aquilo que se quer dizer aqui ${ }^{5}$; mas até agora não se apresenta nenhum mais adequado.

\section{Recebido: 19/01/2018}

Aceito: $25 / 04 / 2018$

${ }^{1}$ Paula Alves é tradutora, graduada em Letras Português-Alemão e mestre em Teoria Literária e Literatura Comparada pela Faculdade de Filosofia, Letras e Ciências Humanas da Universidade de São Paulo. paulaama@ hotmail.com

2 Faculdade de Ciências Médicas da Santa Casa de São Paulo - FCMSCSP - São Paulo (SP), Brasil. E-mail: messas@fenomenoestrutural.com.br

3 A história da "dialética", no sentido que gostaríamos de apresentar, não começa apenas - sob o pano de fundo da escola eleática (Boeder, 1968) - com a história do termo em Platão. Já em Heráclito (fragmento n. 8, 10, 15, 32, 49a, 51, 60, 88), encontramos aproximações a uma perspectiva dialética, bem como em alguns usos do Tao-te-king de Lao-Tsée.

${ }^{4}$ Cf. Bubner, Cramer e Wiehl (1970); Diemer (1976); Perelman (1970); Röd (1974); o volume 21 de Studiums generale (1968); a revista Dialectiva, entre outros. Mencione-se de alguns autores: Adorno (1966, 1971); Barion (1976); Becker (1969, 1970); Bloch (1977); Heiss (1959); H. Y. Jung (1977); Kuhlenkampff (1970); Perelman (1970); Petersen (1980); Rademacher (1973); Waldenfels (1977). Rychlak (1976) trata os diferentes significados de "dialético" especialmente quanto à psico(pato)logia e à psicoterapia.

5 Tem-se aqui em vista a pergunta sobre a possibilidade de integração do negativo, adverso ou também contraditório por meio de uma flexibilidade categorial (isto é, através de uma mudança do ponto de partida ou do quadro de referência). Lembre-se do duplo sentido da palavra "desilusão": seria presentificada a dor que uma desilusão pode ocasionar, e - até onde isso dê certo -, ao mesmo tempo, o significado literal, segundo o qual cada "des-ilusão" nos aproxima um passo da verdade. Rickert (1921) - aqui eu sigo as indicações de Diemer (1976) - pretendia colocar no lugar de uma negação dialética um "princípio heterológico". Ele postulava que "a alteridade precede a negação. Logicamente, algo mais originário do que a 
Quando falamos da "relação com o negativo", este último é, sem dúvida, ambíguo. Pode dizer respeito a um juízo isento ou depreciativo ("não é" ou "não deve ser") - nosso mesmo [150] ou de um objeto tornado sujeito - ou à negação fática, à ameaça, à remoção, à eliminação, à destruição de algo por algo outro. A contestação da sentença da contradição e do terceiro excluído contém apenas uma forma de dialética. Em todo caso, trata-se aqui da decisão de tomar algo "negativo" como negativo (seja ideal, seja real) ou então como a-ser-integrado (quer dizer, como impulso para um processo que continua ao nível da valoração, da constatação ou de um passo real de desenvolvimento). Em qualquer caso é possível diferenciar umas das outras tendências de exclusão e de integração.

É evidente a imediata orientação para a prática de nossa problemática, se formulada dessa maneira. Constantemente, quando temos um paciente diante de nós (seja nas visitas clínicas, na psicoterapia individual, em grupo ou também fora, na vida cotidiana), estamos diante da pergunta de como se deveria apreender aquilo que ele vivencia como "patológico" em si e/ou os outros nele. A experiência humana se desenrola - em sentido respectivamente diferente - em dois níveis: ou definimos aquilo que vem ao encontro a partir das nossas categorias disponíveis, do que nós não nos desembaraçamos sem a negação - omnis definitio est negatio -, ou tomamos a adversidade naquilo que vem ao encontro não como ensejo para uma negação, mas como estímulo para revisar e transformar a nós mesmos - a nossa organização categorial. No primeiro caso, mantemos diante do que vem ao encontro nosso sistema categorial; a experiência refere-se, então, apenas ao conteúdo, ao fático. No outro caso, aprendemos algo ainda em um outro nível. Nós obtemos da experiência a coerção para mudar nossa organização categorial e assim, afinal, também nós mesmos.

A forma mais simples de uma positividade (aqui apenas: efeito positivo) do negativo vem expressa na sentença "aquilo que não nos mata, fortalece": aquilo que já existia pode se fortalecer através do confronto com o negativo, sem com isso se modificar. Mas somente se falará de dialética quando ocorrer não apenas uma mudança quantitativa, mas uma reorientação qualitativa.

Já se pode constatar: para a manutenção ou não manutenção da abordagem dialética não há critérios estritos, não há possibilidades de verificação ou falsificação. Trata-se, antes, de uma questão de "adequação" - não da correção ou [151] incorreção. Seria errado, no entanto, querer reduzir o problema a algo puramente pragmático, isto é, ao problema da praticabilidade do procedimento. Certamente, a prática não se deixa omitir e, com ela, também não se deixa omitir o ponto de vista prognóstico, quer dizer, o respectivo futuro, que decide se algo se mantém ou não. Todavia, trata-se de teoria, mas de uma teoria da prática, e isso em duplo sentido: tanto de uma teoria da relação prática com o que vem ao encontro, como da teoria enquanto uma forma determinada de prática de acordo com o manejo da realidade.

Lê-se, então, da seguinte maneira a pergunta “qual é o alcance da abordagem dialética na psiquiatria?”: quando se deve aceitar um "não" como apenas um não, com todas as consequências de disposição e comportamento que daí resultam; quando como uma indicação para mudar o quadro categorial de

alteridade... não pode de forma alguma ser pensado" (Rickert 1924, p. 24; cf. a esse respeito também Flach [1959]). De fato, trata-se frequentemente da confrontação com o ser outro. Neste sentido, pode parecer legítimo substituir "antítese" por "heterotese" (o "pensamento colateral" de S. Kierkegaard [Malantschuk, 1970] aponta em direção análoga, para o que Eng [Lexington/Usa] chamou pessoalmente a atenção do autor). Mas todo ser ou tornar-se outro significa afinal a negação de um permanecer-idêntico-a-si-mesmo. Consequentemente, está implicada também nesta abordagem uma relação com o negativo. Esse conceito de negativo é muito amplo. Uma vez que a "positividade de um negativo" é posta aqui para o debate como uma pergunta aberta, não como postulado ou princípio, não se deve ver aí nenhum prejuízo. Theunissen (1980, p. 247 et seq.) mostra que a problemática pendente se apresenta de modo mais complexo do ponto de vista filosófico. 
compreensão e enfrentamento? Quando podemos e devemos nos dar por satisfeitos com a negação (o que na prática geralmente inclui um querer eliminar), quando ela deveria se tornar ocasião para contemplarmos uma posição a partir da qual possivelmente resultariam novos aspectos, a partir da qual o suposto negativo não mais se apresentaria apenas como negativo? ${ }^{6}$ Para o observador, isso significa que ele deve estar pronto para questionar seus parâmetros, seu horizonte de compreensão - sim, ele próprio; para a matéria: que deve ser considerada uma metamorfose de seu quadro de referência (e assim, ao mesmo tempo, uma mudança do plano ontológico no qual nós o vemos estabelecido).

A questão sobre a positividade do negativo se deve, evidentemente, a Hegel ${ }^{7}$. Provém dele a tentativa mais duradoura de tornar como base metodológica da pesquisa científica ${ }^{8}$ o entendimento de que "o negativo é igualmente muito positivo" (1958 et seq., IV, p. 50) e a negatividade "o princípio de toda vitalidade natural e espiritual" (ib., p. 54). O que diferencia a presente abordagem daquela de Hegel é que a positividade do negativo não é utilizada como um princípio que constrói sistema, que determina o contexto da experiência, mas tão somente como um princípio heurístico. Tanto quanto sua aplicabilidade, vale ter em vista, seriamente, a resistência (maior ou menor) do que cada vez vem ao encontro contra tentativas de interpretação dialéticas. Ao perguntarmos pelo alcance desse princípio, tentamos desenvolver uma sensibilidade não só para as possibilidades de uso, mas também para os limites do mesmo. Poderíamos muito bem falar também de uma "dialética" entre disposição não dialética e dialética.

[152] Como facilmente se percebe, a questão sobre o alcance da abordagem dialética extrapola as disciplinas individuais e a filosofia. Ela não se limita, de modo algum, à relação cognitiva com o mundo, mas envolve o confronto pré-teórico (até mesmo pré-consciente), imanente à vida humana, com o negativo. A forma mais radical dessa confrontação é aquela com a própria morte. Por isso, a abordagem dialética também tem, visivelmente, um antecedente na relação religiosa com o mundo, para nós mais próxima no cristianismo, enquanto a religião de morte e ressurreição. Não só para Kierkegaard, também para a compreensão dialética de Hegel, isso é evidente: "mas não a vida que se

\footnotetext{
${ }^{6}$ Essa compreensão de dialética corresponde, em grande medida, a de Strasser (1961, p. 148 et seq.): "Por dialética eu entendo... toda mudança ordenada do ponto de vista, que permite superar sistematicamente horizontes limitados". Isso não vale aqui apenas quanto ao nosso horizonte de compreensão, mas também quanto ao do paciente. Tem-se em vista aí não só a parte capaz de consciência de sua compreensão do mundo e de si, mas todo o quadro de referência daquilo que se evidencia através de sua vida. Algumas de minhas formulações anteriores, como "todo meramente negativo, que nos depara, mostra que não basta o esboço que deixa a ocorrência entrar no campo de visão como negativo... deve se tornar para nós um indicador de que o esboço... deve ser modificado" (Blankenburg, 1958, p. 102), eu não deixaria hoje nessa forma generalizante, porque ela não libera suficientemente a pergunta enquanto tal, a saber, quando uma abordagem dialética está no lugar e quando não. Contudo, tudo que parece deficitário deveria ser examinado à luz da suficiência ou não do quadro de referência, a partir do qual isso se apresenta como deficitário. Isso significa, para a psiquiatria, que conceitos como "anormal" e "doente" - ao menos em sua periferia - entram em movimento; reconhecidamente, um movimento perigoso, que exige uma grande medida de ponderação crítica. A pergunta "qual o alcance da perspectiva dialética na psiquiatria?" gostaria de alertar tanto sobre uma sobrestimação quanto uma subestimação desse alcance.

${ }^{7}$ Não somente Hegel. Topitsch (1976) fala, em relação à dialética, sobre "formas de pensamento perenes" de interpretação do mundo e de si, que - já manifestas nos mais antigos documentos da humanidade - possuiriam uma tenacidade impressionante. Essa tenacidade não precisa de ter razões exclusivamente psicológicas e sociológicas (cf. sobre crítica à dialética, além de Topitsch, também Wuchterl [1977]; Popper [1976]; Albert [1971], entre outros), ela poderia muito bem em grande parte ser fundamentada na própria coisa - quer dizer, na particularidade da relação humana consigo e com o mundo.

${ }^{8}$ Mas não se trata apenas do curso de experiências do sujeito investigador, mas também, em igual medida, daquele do sujeito investigado; em nosso contexto, do desenvolvimento da relação consciente bem como inconsciente ou pré-consciente do paciente consigo e com o mundo.
} 
acanha diante da morte e apenas se preserva da devastação, mas que a suporta e nela se mantém, é a vida do espírito [...]" (1958 et seq., II, p. 33). Pode-se, por isso, compreender a dialética nessa figura também como a tentativa de "cristianização" do pensamento e do experienciar. Seria obtuso, contudo, mirar aqui apenas a relação cristã consigo e com o mundo. Quase todas as culturas antigas festejaram a renovação (renascimento) através da morte em seus mitos, cultos (por exemplo, ritos de iniciação) e mistérios. A partir disso, podemos estigmatizar o método dialético ou como uma irrupção atávica de uma compreensão de mundo pré-científica no pensamento científico, ou então aceitá-lo como o resultado de uma confrontação mais radical (porque também integra a si mesma) do pensamento e do experienciar com a realidade (e então aceitá-lo como uma etapa suplementar do se envolver tanto prática quanto teoricamente com a realidade).

Em contraste com isso, é possível pensar em uma interpretação psicoanalítica: entre os dez mecanismos de defesa, descritos por A. Freud (1968), encontra-se a "identificação com o agressor" (como uma "etapa de transição nada incomum no desenvolvimento do super-eu do indivíduo" [p. 90]). A pessoa em questão tornaria inócua a adversidade que vem ao seu encontro introjetando-a, ou melhor, identificandose com ela. É corrente o exemplo da criança que supera o medo de fantasmas ao brincar ela mesma de "fantasma". Em Para além do princípio de prazer (1920/1972), S. Freud ressaltou particularmente o significado dessa inversão de passividade em atividade para a elaboração de vivências desprazerosas ou traumáticas da vida infantil. A. Freud entende o "objeto do medo" (Angstobjekt) como agressor. Mas não precisa se tratar necessariamente de uma pessoa. A abordagem pode ser facilmente expandida se a despersonalizamos. A pessoa em questão introjeta então não "algo da pessoa" do [153] agressor (1968, p. 88), mas de modo bem geral algo da essência da adversidade que vem ao seu encontro ou da regularidade, sob a qual esta se acha. Essa é em geral uma maneira pela qual nós revidamos ao mundo, pensando. Nessa altura, interessa apenas que nós podemos interpretar o tomar positivamente o negativo (como elemento fundamental da relação dialética com a realidade) como uma "identificação com o agressor", sem precisarmos com isso recair em um reducionismo.

Contudo, podemos duvidar se se trata aí em todo caso de um mecanismo de defesa. Antes, pode-se ver nisso de modo bem geral uma forma possível de manejo do que vem ao encontro como um todo aconteça isso, então, no caso particular, por motivação inconsciente (sob recalque da adversidade do adverso), pré-consciente, consciente ou até mesmo com uma grande e refletida consciência. Afinal, toda dominação ponderada da realidade baseia-se em uma internalização de ocorrências (primeiramente estranhas, quer dizer, que negam nossas expectativas, des-ilusão) em nosso entendimento, ou melhor, de suas regularidades; baseia-se, então, em uma crescente "introjeção" das mesmas. Seria um experimento interessante interpretar, a partir dessa abordagem, as bases apriorísticas do conhecimento humano como quintessência de tais introjeções.

Mas, no presente contexto, não se trata de esclarecimentos filosóficos que se satisfazem a si mesmos, mas dos fundamentos da psicopatologia, da nossa relação com o psiquicamente anormal, na medida em que esse anormal parece anunciar uma deficiência, um menos na saúde anímica. Nossa questão é então: quando se deve entender sem mais uma deficiência psicopatológica como tal, quer dizer, como algo que não deve ser e, de acordo com as possibilidades, a ser eliminado; quando como indício de que aqui um outro plano da existência humana tenta se efetivar - por malsucedido que seja? Isso significa abrir mão da "restitutio ad integrum" enquanto diretriz única ou mesmo dominante para o pensamento e ação terapêuticos. Doença não é mais vista generalizadamente como uma negação da saúde enquanto tal, mas como negação de uma determinada saúde, que, através do transtorno que se instala, é carimbada como algo que já foi, agora "inverídico", talvez até mesmo desmascarada como uma saúde já antes enganosa ("pseudo-saúde”). Assim, a doença ganha um sentido de orientação irreversível. De 
um processo natural, ela se torna um acontecimento "histórico". Com isso, aponta-se para uma guinada fundamental na perspectiva; [154] uma guinada, que - dando nova vida a abordagens do início do século XIX - fez escola na "medicina geral" de V. v. Weizsäcker. Ali, de início, seguindo a tradição de L. v. Krehl e R. Siebeck, fez-se um problema da dimensão histórica do adoecer em toda sua extensão.

Certamente, também a psicanálise se ocupa - até mesmo muito intensamente - com a história de vida do paciente individual; contudo, não primariamente como história. Tematicamente, é precisamente o a-histórico ou o pseudo-histórico nela (mecanismos inconscientes, por exemplo, as compulsões à repetição, entre outros), isto é, precisamente aquilo que se destaca do que é histórico no curso de uma vida. Isso seria, todavia, dificilmente possível, se afinal a historicidade não funcionasse ${ }^{10}$ no pano de fundo como um critério - por meio disso, indiretamente, a psicanálise contribuiu bastante para um conceito mais preciso de historicidade. Contudo, justamente esse pano de fundo não é por ela explicitado. Afinal, uma problemática causal-genética-determinística domina o campo. Nisso a psicanálise pouco se diferencia das demais pesquisas patogenéticas. Não entra em vista a doença como acontecimento histórico, que não só transforma a perspectiva de vida do paciente, mas é também capaz de problematizar a compreensão de saúde/doença do médico. O presente é visto na sua determinação pelo passado. O futuro vale no máximo como dedutível per extrapolationem a partir do passado e do presente, sem que seja incluído como uma dimensão própria.

A doença somente ganha um aspecto propriamente histórico quando não apenas os fatores que a condicionam, mas também os critérios pelos quais a medimos são vistos em movimento. Metodologia dialética, como a entendemos aqui, não é tanto uma determinada interpretação desse movimento, mas, antes, um instrumento para torná-lo antes de mais nada visível e experimentável. A relativação do conceito de doença, que se torna necessária a partir dessa abordagem, encontrou sua expressão mais clara no postulado paradoxal de uma "doença de não conseguir ficar doente" ${ }^{11}$. Se é verdade que o livro de Müller-Eckardt (1954), que carrega esse título, não satisfaz - as evidências que ele traz parecem em parte anedóticas -, não obstante, nele se articula de maneira suficientemente clara, como de modo geral em todo o movimento dessa "medicina antropológica", muito antes do advento da dita

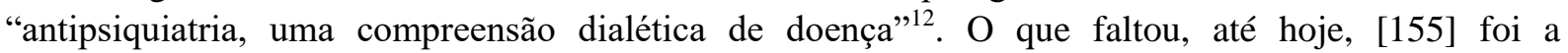
verificação crítica e ponderada dessa abordagem. Tal falta fez com que a problemática enquanto tal não fosse levada a sério cientificamente e quase recaísse no esquecimento, até que então ela chamou novamente a atenção ao metamorfosear-se na figura da "antipsiquiatria", muito menos autocrítica e, em contrapartida, tanto mais afeita à crítica externa. A diferença entre a visão mais antiga, orientada para a história do indivíduo, que possui em parte um fundo religioso, e a visão crítica sociológica e socialmente, de proveniência marxista, não deve iludir a respeito do estreito vínculo entre essas duas correntes. Em Siirala (1963), encontram-se já delineamentos desta última. A crítica à "antipsiquiatria"

\footnotetext{
${ }^{9}$ Entendemos por "historicidade" o fato de que há incidentes que possuem um caráter de acontecimento no sentido de que 1) transmitem a impressão de unicidade, irrepetibilidade, 2) possuem um sentido de direção no futuro e 3) não estão apenas, como outros fatos, sob leis, mas, para além disso, geram eles mesmos quadros de referência; cf. de resto a vasta literatura sobre o conceito de historicidade, sobre o qual não trataremos aqui (Blankenburg 1981)

${ }^{10}$ Sobre isso escreveu-se muito; cf. Lang (1978), entre outros.

${ }^{11}$ Nessa altura, poderíamos citar também uma paciente de Lechler (1976): "Na verdade, o mais saudável é a doença" (p. 94).

${ }^{12}$ Entre outros aspectos, recorde-se do conceito de individuação de C. G. Jung. Seifert destacou já em 1935 em que medida ele possui caráter dialético. Que também a concepção de Adler carrega traços dialéticos mostra Ansbacher (1977).
} 
(Glatzel 1975; Kisker 1979) não deve recair no erro, como antes o fez a crítica à "medicina antropológica" (Weitbrecht 1955), de menosprezar como "tendência na moda" esse movimento, por causa da desproporção nele evidente entre crítica externa e autocrítica. A leviandade de algumas afirmações de autores de ambas as correntes lamentavelmente levou a que, tanto entre seguidores quanto entre críticos, a questão subjacente - "qual é o alcance da abordagem dialética? Em que medida é justificada, em que medida não" - não fosse levada suficientemente a sério enquanto questão ou até mesmo nem fosse colocada.

Na presente abordagem, a perspectiva dialética se liga à fenomenológica. Isso implica uma série de problemas, que aqui só podem ser brevemente esboçados: a fenomenologia, na medida em que torna visíveis estruturas eidéticas, isto é, comporta-se descritivamente, não é em sua essência necessariamente antidialética? A pergunta parece legítima. Uma tendência antidialética é perceptível pelo menos na fenomenologia de E. Husserl. Contudo, fenomenologia e dialética não se excluem de maneira alguma (Fink 1975; Funke 1960; Landgrebe 1960; Strasser 1961; Waldenfels 1977; Wiehl 1970). Sobretudo o desenvolvimento da fenomenologia na França mostra isso, onde ela bem cedo absorveu a tradição dialética - tanto a hegeliana quanto a marxista (Goldmann, Merleau-Ponty, Sartre, Derrida, entre outros $)^{13}$. Pensemos também no debate que perdura até hoje em alguns países eslavos, que nos últimos anos se concentrou em Dubrovnik (Waldenfels et al. 1977 até 1979).

Encontram-se, em Heidegger (sobretudo nos trabalhos de juventude), diversas estruturas dialéticas, das quais algumas entraram na psiquiatria através da Daseinsanalyse ${ }^{14}$ (como, por exemplo, ser projetando [Entwerfendsein]/ [156] dejecção [Geworfenheit], desvelamento [Entborgenheit]/encobrimento [Verborgenheit], desmundificação [Entweltlichung]/mundanização [Verweltlichung], entre outros). Mas o dialético em Heidegger é, em parte, novamente revogado através da ênfase no elo basal e "origem idêntica" de momentos estruturais antagônicos. De resto, a relação de Heidegger com o pensamento dialético ${ }^{15}$ é complicada demais para que possa ser explicada aqui.

Também ambivalente, embora em muitos aspectos distinta, é a relação de L. Binswanger com a abordagem dialética. Em 1920, ele acreditava ter encontrado na dialética entre instâncias que representam a norma e instâncias que rejeitam $a$ descoberta essencial da psicanálise e, ao mesmo tempo, a sua base ${ }^{16}$. A obra Formas elementares e conhecimento da existência humana (1943/1964) trata sob os títulos de "preocupação" e "amor" o movimento dialético entre basear-se em uma subjetividade isolada transcendental ("eu-dade" [Jemeinigkeit] da existência) e basear-se em uma intersubjetividade constitutiva; em suma: uma dialética entre a fundamentação do eu e do nós, tal

\footnotetext{
13 Kopper (1957), Nauta (1968), Rabil (1967), Seel (1971), de Waelhens (1951) transmitem balanços sobre a relação do pensador individual com a dialética.

14 A tradução do termo "Dasein" para o português é controversa, particularmente no contexto da tradução dos escritos de Heidegger. Trata-se de um termo com muitas nuances, utilizado em uma diversidade de situações, mas que também pode ser empregado no uso corriqueiro, e nesse sentido, remete à "existência", "presença". Nesta tradução, optou-se por traduzir em geral as ocorrências da palavra "Dasein" por existência, a não ser quando há claramente uma outra tradução consagrada na literatura internacional, como neste caso.

15 Quanto à crítica da Heidegger sobre a dialética tradicional como "maior incremento" da "dominação do logos", cf. Kanthack (1968).

16 A obra de Freud é, em grande medida, marcada se não por um pensamento dialético, então por um pensamento por oposições (cf. Gnädinger, 1976). Taubes (1970) vê relações mais estreitas com a dialética de vertente marxista.
} 
como ela subjaz, de maneira mais ou menos evidente, a muitos trabalhos fenomenológicos recentes ${ }^{17}$. Uma vez que as abordagens dialéticas, nos passos seguintes de Binswanger, foram paralisadas por um pensamento também cada vez mais orientado por estruturas fixáveis, então Gabel (1967) não estava totalmente errado ao interpretar Binswanger como um dialeta disfarçado ${ }^{18}$. Um estudo próprio (Blankenburg, 1981) mostra o quanto é fácil dar uma guinada dialética a uma concepção (que, a primeira vista, parece tão estática) como a de "proporção antropológica".

Pertence à Daseinsanalyse uma ampla oscilação entre empatia participativa e distância contemplativa ou reflexiva. A última eventualmente deu ocasião para o equívoco de que seria assumida aqui a posição do "observador distante" (Stierlin 1975), alheio (Foudraine 1976). Isso engana. Visa-se, antes, um movimento pendular entre extrema imediaticidade na relação participativa com o paciente e reflexão contemplativa do que se ficou sabendo através dela. O terapeuta deveria ser capaz de se questionar a cada momento, sempre de novo, a respeito de sua própria posição e maneira de ver, de modo a permanecer aberto tanto para uma possível negatividade do aparentemente positivo quanto para uma possível positividade do que a princípio parecia apenas negativo ou deficitário. Recentemente, Kimmich (1978, p. 198-213) mostrou em pormenor que o conhecer antropológico é possível através da superação dialética da oposição entre conhecimento objetivante e não objetivante [157] e ressaltou que o perceber que se opera nesse caso, não apenas na medida em que está em uma relação objetivante, mas também na medida em que está em uma relação não objetivante, ocorre juntamente com um pensamento que reflete sobre essa relação. Consoante a isso, não é possível um conhecimento fundado cientificamente da existência humana (Menschsein) sem uma "antropologia do conhecimento" (Wein, 1974), um conhecimento sobre o que está de acordo com o homem sem uma "adequação ao homem" do conhecimento (cf. também Giorgi 197b; Blankenburg 1975, 1978a, 1979). O círculo hermenêutico que se faz notar nessa formulação é um tal que, podemos dizer com Heidegger (1927), não se trata de escapar dele, mas, antes do mais, de ser arrastado para dentro dele. Ele constitui um problema fundamental da pesquisa antropológica e, com isso, também da psico(pato)logia orientada antropologicamente.

Para a psiquiatria, em relação a cada paciente individual, está em jogo "uma determinada 'dialética' do humano", que "é melhor apreendida como dialógica" (Kisker, 1970a), no sentido de um se constituir reciprocamente; e, nesse contexto, não apenas se constituir do eu e do outro (por exemplo, relação médico-paciente), do eu e do nós (subjetividade-intersubjetividade), mas também está em jogo uma "coexistência entre razão e desrazão". A solidariedade com o psiquicamente doente, que se torna possível sob esse pano de fundo, não pode ser compreendida adequadamente, de acordo com Kisker (1970a), nem como contratransferência, nem como reação induzida. Ela ainda irá nos interessar enquanto base de uma psicoterapia antropologicamente fundada da neurose e, sobretudo, da psicose.

É sobretudo o conceito de "crise"19 que ganha contornos mais precisos através da perspectiva dialética, para além tanto do seu componente ligado à tradição, quanto do seu componente persuasivo

\footnotetext{
17 Aqui remeteríamos à vasta literatura sobre o problema da intersubjetividade (Theunissen [1968/1977]; Kisker, [1969]; Waldenfels [1977]; Orth [1977]; Schäfer [1980]; Brand [1978]).

${ }^{18}$ Segundo Kimmich (1978, p. 212), nós devemos ver como um mérito de Binswanger "ter introduzido de modo terminante a dialética na antropologia", e, mais precisamente, como uma dialética "auto-obtida da hermenêutica da existência humana".

${ }^{19}$ Quanto a publicações recentes sobre o conceito de crise, cf. as palestras e discussões no 7. Simpósio de Donau de Psiquiatria, sumarizadas por Berner e Gabriel em Psychiatria clin. 10 (1977); sobretudo, Reiter e Strotzka (1977), Scholmerich (1978), bem como Koselleck, Tsouyopoulus e Schönpflug (1976). Recorde-se a controvérsia na história recente
} 
e na moda (Reiter e Strotzka 1977). Falamos de crise em sentido estrito, quando um quadro de referência antes válido (seja ele predefinido ou por nós criado) ameaça perder seu significado ou não leva mais adiante. Esse "não mais" se impõe de início como mero risco, como negação (= possível perda) de uma estabilidade antes preservada. Não se trata de contestar, por exemplo, a negatividade ou adorná-la. Mas a pergunta se dirige para aquilo que é então aqui negado ou afetado. Comumente, negações acontecem de modo retroativo. Quer dizer, aquilo, a partir do qual se mede, a partir do qual se constata um prejuízo, refere-se a algo que existia antes, que estava antes fixado ideal ou realmente (por exemplo, uma determinada norma de saúde, [158] uma norma de comportamento, ou melhor, da capacidade e situação de se comportar [Blankenburg 1978a]). Mas o "não mais" de algo pode eventualmente ser ao mesmo tempo o "ainda não" de algo totalmente diferente. A crise, então, não é apenas uma "lacuna" ou uma ruptura ameaçadora na continuidade do desenvolvimento histórico de uma vida, mas também um hiato entre o não mais e um ainda-não. Tanto ao sujeito do observador (isto é, o terapeuta) com sua concepção transcendental (fundada intersubjetivamente) de saúde e doença, quanto ao próprio doente com sua própria concepção de si é imposta uma mudança fundamental (em relação ao quadro de referência e os parâmetros a ele adequados), que pode significar fracasso ou inovação.

No conceito de crise podem ser demonstrados, de modo paradigmático, traços essenciais da perspectiva dialético-antropológica, sem que esta se deixe reduzir a ele. A pergunta sobre uma possível positividade do negativo (como sobre uma possível negatividade do positivo) não se esgota nisso. Contudo, visto que o negativo se apresenta aqui como futuro, negando o presente e o passado, torna-se evidente em que medida essa abordagem contribui para a exposição da dimensão histórica da existência humana (e, assim, também do estar psiquicamente doente $\left.{ }^{20}\right)$.

Qual é, então, concretamente, o alcance da perspectiva dialética em relação a síndromes psicopatológicas singulares, com as quais nos deparamos no cotidiano psiquiátrico? Se queremos assumir uma posição crítica, seria recomendável já de início perguntar ao contrário: onde ela não alcança, onde esbarra em limites, em impedimentos? Aqui devemos estabelecer diferentes distinções: 1) nossa visão, 2) a atitude consciente do paciente, 3) sua atitude inconsciente e, resultando dela, o experienciar de tal ou tal maneira, o sofrer de tal ou tal maneira ou também o dominar de tal ou tal maneira a situação que se transformou no decurso da doença; sem que, até hoje, seja possível dizer em muitos casos em qual extensão tentativas de elaboração e dominação já estão implicadas naquilo que chamamos de "doença psíquica" ou onde se deve estabelecer os limites entre prejuízo "primário" e sua elaboração "secundária".

Ao ressaltar a pergunta sobre o alcance da abordagem dialética, nós nos voltamos tanto contra determinadas antecipações ideológicas de respostas a essa pergunta (quer dizer, contra afirmações infundadas, como é comum, por exemplo, na "antipsiquiatria", por exemplo na forma: [159] a esquizofrenia seria uma reação em certa medida saudável a uma estrutura social patológica); quanto

da psiquiatria entre Kulenkampff (1959) e K. Conrad (1959) sobre o conceito da "crise anormal”. Cf. também: Dörner (1979, p; 805 et seq.) e Wölff (1976).

${ }^{20}$ Em alemão, a correlação aparece também nas palavras que o autor utiliza: de um lado, menschliches Dasein, de outro, psychisches Kranksein. 
contra uma psicopatologia que nem sequer levanta tais perguntas - quer dizer, contra a recusa de sua "questionabilidade" ${ }^{21}$ nos dois sentidos da palavra.

Sob esse aspecto, parece evidente partir das síndromes mentais orgânicas. Psicoses exógenas agudas, síndromes psico-orgânicas crônicas, deficiências no desempenho cerebral, demência ${ }^{22}$ e deficiência mental parecem ridicularizar qualquer perspectiva dialética. No entanto, há também aqui exemplos que deixam uma positividade do negativo aparecer ao menos como considerável. A transformação da personalidade na epilepsia pode também ganhar lados positivos, se se pensa no rigor, obstinação, confiabilidade, apego e fervor da vida sentimental que impressiona em muitos epiléticos. Dostoiévski tornou algo disso visível não só em figuras específicas de seus romances ${ }^{23}$, como também mais ainda em sua própria vida e criação. Nele, até mesmo a circunstancialidade, assim como a viscosidade dos epiléticos torna-se um meio estilístico próprio. Quando sondamos outras doenças cerebrais orgânicas, esbarramos na paralisia de Nietzsche, cujos estados preliminares (que até hoje não podem ser delimitados cronologicamente com precisão) tingiram a particularidade de suas últimas obras (sobretudo o sobrevoo à maneira de Ícaro, antes do colapso). Por fim, mas não menos importante, sob essa impressão Thomas Mann exaltou na figura de Adrian Leverkühn a paralisia progressiva enquanto um instrumento de demonização do humano. A realidade clínica, em contrapartida, parece na maioria das vezes banal e desenganadora. É bom, contudo, manter-se aberto aos fenômenos limites, já que despontam não apenas em gênios, mas, às vezes, também em pacientes do cotidiano clínico - mas sem sobrevalorizá-los. É possível extrair ganhos até mesmo da deficiência mental, se pensamos, por exemplo na síndrome de Down: o mundo seria mais pobre, sem o calor anímico que pode ser vivenciado no convívio com as pessoas portadoras dessa síndrome; e nisso devemos observar, também, como aqui a análise não se limita ao indivíduo doente, mas inclui enquanto realidade aquilo que acontece no inter-humano. Trata-se aí, contudo, basicamente de exceções, de fenômenos limite em meio a uma abundância de doenças cerebrais orgânicas e más-formações que contrariam qualquer perspectiva dialética.

Além disso, criticamente seria possível registrar que nessas "exceções" não se trataria de forma alguma de uma viragem do negativo em positivo [160], mas de "lados positivos" ocasionalmente observáveis ao lado do negativo. Mas essa objeção não procede, na medida em que aqueles aparecem indissociavelmente ligados ao patológico.

A depressão endógena vale como um outro exemplo marcante do quanto os transtornos mentais podem escapar de uma perspectiva dialética. Sobretudo Weitbrecht (1955) salientou repetidamente o fato de que fases endogenamente depressivas raramente provocam uma reorientação existencial, apesar de toda a confrontação com culpa e frustração e nulidade da existência. Pelo contrário: apenas em outras poucas doenças salta tanto aos olhos uma restitutio ad integrum depois do desaparecimento

\footnotetext{
${ }^{21}$ Em alemão, "Frag-würdigkeit". Decompondo a palavra, Blankenburg evidencia que não se trata apenas da característica do que é questionável; questionabilidade refere-se também àquilo que merece (-würdig) ser questionado.

${ }^{22}$ Gadamer (1964) vê, contudo, até mesmo nas doenças psiquiátricas que acompanham a demência uma "perda humana de equilíbrio", que, como toda perda de equilíbrio, deveria ser pensada "dialeticamente".

${ }^{23}$ Dentre as inúmeras publicações sobre esse tema mencione-se sobretudo o caderno I do Jahrbuch für Psychologie, Psychotherapie und medizinische Anthropologie 14 (1966), que contém 11 trabalhos, estudos e seminários de revisão bibliográfica sobre a visão fenomenológica-antropológica sobre a epilepsia, com referência particular às figuras epiléticas de Dostoiévski (resultado de um seminário de Janz e Tellenbach [1965]), bem como Gastaut (1979), que se refere a uma linha de outros epiléticos geniais como Flaubert e van Gogh.
} 
dos sintomas: um retorno - se quisermos, uma "recaída" - ao status quo ante escarnece de toda abordagem dialética. A depressão que transcorre em fases, tal como ela se apresenta frequentemente no cotidiano psiquiátrico, é algo extremamente a-histórico. A isso corresponde uma estrutura "adialética" da personalidade pré-mórbida de pessoas com depressão. Kraus (1977), seguindo Tellenbach (1976), interpretou a "constituição da identidade" desses pacientes como "anulação de estruturas existenciais dialéticas". Essa falta de dialética na relação imediatamente expressa com o mundo e consigo já resulta das investigações mais antigas de Fränkel-Brunswik (1948), nas quais se comprovou uma intolerância à ambiguidade em depressivos. Uma tal intolerância à ambiguidade ${ }^{24}$ deve ser vista como expressão de uma fixação muito rígida em um determinado esboço de vida ("includência", segundo Tellenbach [1976]). Não será discutido aqui até que ponto a reestruturação de depressivos - algo, então, como uma "dialetização" da relação consigo e com o mundo - representa um objetivo concretizável para a terapia ou até que ponto ela representa um postulado que nos sobrecarrega. Todo aquele que se esforçou nessa direção sabe que a tentativa de uma restruturação desses pacientes no sentido de uma dialetização de sua prática vital, de sua atitude de vida, de sua visão de vida esbarra em resistências que se ancoram visivelmente muito fundo. $O$ fenômeno desse resistir é enquanto tal interessante. Ele indica que a perspectiva dialética na psiquiatria pode sensibilizar não só para o dialético, como também para o não dialético no comportamento dos pacientes que vem ao nosso encontro.

Com isso, passamos subitamente do dialético de uma "perspectiva" para o dialético ou não dialético de seu objeto. Esse é um "shift" que não deveria ser visto como imprecisão metodológica, mas que resulta quase necessariamente da correspondência entre noesis e noema.

Nas depressões reativas e neuróticas as coisas são diferentes. Para elas, não vale o que foi dito. Enquanto expressão de crises biográficas, elas praticamente incitam a uma entrada e processos dialéticos. Em relação a elas - desde que não se tornem crônicas - o lema que se tornou título de livro, "Depressão como oportunidades de vida" (Flach 1975), pode ser totalmente legítimo. Precisamente ali, onde depressões, enquanto "dores de crescimento da personalidade", mostram o hiato entre um não mais e um ainda não; são, portanto, expressão de "crises" em sentido estrito, com o que devemos entender - como referido anteriormente - agravamentos à maneira de crescendo da biografia, os quais deixam uma reorientação categorial aparecer como necessária ${ }^{25}$.

Nesse contexto, coloca-se a questão de saber se ou em que medida depressões "existenciais"26 (como, por exemplo, a "melancolia" no sentido de Kierkegaard) poderiam ser separadas de depressões "neuróticas". Até hoje ela é respondida de maneira controversa. A resposta depende, em medida nada desprezível, das definições subjacentes. Pode-se argumentar que se trataria, nas depressões neuróticas, de síndromes de deficiência (condicionadas através de mecanismos neuróticos), que poderiam ser explicáveis através da história de vida; depressões existenciais, por sua vez, seriam expressão não de conflitos insolúveis inconscientes, mas conscientes (no máximo pré-conscientes). A depressão

\footnotetext{
${ }^{24} \mathrm{O}$ conceito de (in)tolerância à ambiguidade foi abordado por uma série de outros pesquisadores (O'Connor [1952], Davids [1955, 1963], Barron [1969]) e desenvolvido com resultados em parte divergentes. O que falta é uma visão sobre a estrutura polar do campo entre intolerância à ambiguidade e entrega à ambiguidade (ambivalência), com o qual temos que lidar na psiquiatria (Blankenburg, 1980).

25 Aqui o autor insere um hífen inusual na palavra, de modo a evidenciar uma camada de sentido menos aparente: notwendig, isso é, aquilo que se dobra à necessidade, à urgência.

${ }^{26}$ Remeta-se à literatura, em grande parte mais antiga, sobre o problema da "depressão existencial".
} 
existencial não brotaria necessariamente de uma falta, mas antes de uma abundância (Überfluss) de saúde psíquica, até mesmo aversão (Überdruss) à saúde psíquica ${ }^{27}$. No entanto, tais diferenciações per definitionem parecem bastante teóricas e quase não se pode sustentá-las diante daquilo que nos vem ao encontro na práxis psiquiátrica e também fora, na vida. Elas pressupõem uma divisibilidade fundamental entre natureza e história. Desenvolvimentos neuróticos poderiam ser interpretados "biograficamente" como comprometimento da "historicidade" apenas na medida em que neles processos naturais ("mecanismos") se sedimentariam de processos biográficos, ao passo que crises existenciais mostrariam antes uma compressão ou potencialização do histórico no curso de vida humano.

Uma tal separação entre "transtorno mental" e "crise existencial" continua a existir, mas aprioristicamente. A experiência médica cotidiana quase não a tem em conta. Além disso, seu pressuposto teórico - uma dicotomia estrita entre natureza e história - é contestável. Ela não considera que cada acontecimento natural, por exemplo, cada tornar-se doente [162], pode ser visto na existência humana também como um acontecimento histórico; pelo menos, ele possui uma importância história, desde que se estabeleça a existência humana de modo geral como histórica.

Nessa controvérsia, nós lidamos com diferentes concepções básicas e é incerto o quanto elas podem ser empiricamente verificadas ou falsificadas. Escolheremos natureza ou história enquanto base da nossa perspectiva? Pensaremos de modo causal-genético ou em categorias da historicidade? Essa escolha também decidirá afinal sobre onde estabeleceremos o limite para o alcance de uma perspectiva dialética. No campo de tal escolha fundamental, o valor de verdade de axiomas subjacentes não deve ser visto de modo independente de sua fecundidade - até que ponto se consegue, com sua ajuda, tornar algo visível e, no final, também, fazer algo "melhor"? - quer dizer, não deve ser visto independentemente de seu valor terapêutico. Finalmente, nossa atitude quanto a essas alternativas também diz algo sobre nós mesmos - diz, para falar com Fichte, "que tipo de pessoa alguém é".

O problema das possibilidades de interpretação e elaboração dialética ou "existencial", bem como de seus limites, diz respeito não só à depressão neurótica, mas aos desenvolvimentos neuróticos como um todo. Isso se deixa ilustrar particularmente bem a partir da angústia livremente flutuante (não vinculada à realidade): alguns autores (como Ringel ${ }^{28}$, entre outros) defendem, por exemplo, a concepção de que a angústia, tal como Rilke a trata em muitas variações de sua poesia, não é, de modo algum, angústia "existencial", mas - sob o pano de fundo de um vínculo conflituoso com a mãe sintoma típico de uma neurose de angústia clássica. A isso se contrapõe a interpretação que o próprio Rilke deu dessa angústia. Pense-se em poemas como "A grande noite" ou o fragmento interpretado por Heidegger" "Como a natureza deixa os seres", nas "Elegias de Duíno" ou "Sonetos a Orfeu"; ainda, na correspondência entre Rilke e V. v. Gebsattel, que evidencia, por um lado, que Rilke percebeu muito bem o patológico, vale dizer, neurótico, sua sintomática de angústia; por outro, contudo, aferrou-se ao mesmo tempo no seu significado para sua criatividade - quer dizer, no seu significado dialético-existencial e, quer dizer, ao mesmo tempo, na sua função de tornar acessível a si e ao mundo. As angústias de separação e abandono que persistem desde a primeira infância ou são reativadas podem ser interpretadas e também elaboradas tanto de modo neurótico-psico(pato)lógico quanto existencialmente - não dialética $e$ dialeticamente. [163] Isso porque separação e abandono são

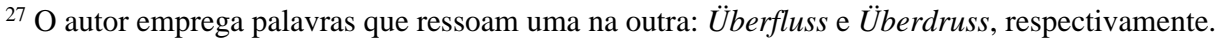

${ }^{28}$ Programa de rádio sobre o $100^{\circ}$ aniversário de R. M. Rilke.

${ }^{29}$ Em: Holzwege (Caminhos de floresta). Frankfurt a.M., Klostermann 1950, p. 248-295.
} 
circunstâncias fundamentais da nossa existência, que de modo geral não foram de fato superadas por aquele que não é por elas assombrado, mas apenas melhor compensadas ou encobertas. Angústia neurótica e angústia existencial não excluem uma a outra. Elas podem se penetrar mutuamente. Nesse caso, não se trata apenas de uma diferença na perspectiva. Há também uma diferença na coisa. A própria coisa, afinal - aqui: a angústia - não independe do modo como a compreendemos e com ela nos relacionamos. Aspectos diferentes indicam diferentes estilos de relação. Isso não significa que a interpretação estaria totalmente sujeita ao arbítrio. Formas diferentes da angústia evocam maneiras diferentes de interpretação e relação: mais dialética ou mais não dialética. A complexa estrutura das relações entre maneira de acesso, de observação, de relação e de domínio em relação a uma "coisa" e a "própria coisa" podem ser aqui particularmente bem estudadas.

Se atribuímos, em princípio, às neuroses um efeito que exclusivamente paralisa a criatividade, como, por exemplo, Kubie (1966), ou se reconhecemos em uma neurose elementos que provocam a criatividade $^{30}$, como foi defendido sobretudo na escola de C. G. Jung, mas também foi e é defendido por outros (Benedetti 1975), isso também se relaciona com a atitude quanto a esse complexo de questões. Isso ainda não está resolvido. Veremos que essa questão se coloca também de forma potenciada quanto às psicoses esquizofrênicas. A resposta depende essencialmente do que designamos como "neurótico" ou "psicótico": uma determinada invasão da estrutura da existência ou somente a sintomática que daí cresce (seja esta então compreendida como uma forma patológica determinada de defesa ou como expressão de uma mera deficiência).

Em um estudo sobre "Histeria na visão antropológica" (Blankenburg 1974/1980), tentou-se tornar fértil para uma compreensão biográfica de neuroses histéricas a perspectiva dialética a que aqui nos referimos. As consequências dessa abordagem não se esgotam no teórico; elas se estendem, antes, até a prática psicoterapêutica ${ }^{31}$. A perspectiva dialética colabora com o terapeuta para uma identificação parcial com aquilo que resulta em um desenvolvimento neurótico. Ela pergunta "contra o que" (contra qual unilateralidade totalmente diferente) pode ter se dirigido originalmente aquilo que, no final, aparece enrijecido na sintomática neurótica. Os modos de comportamento histéricos [164] não são então demarcados simplesmente como "comportamento desviante" de um comportamento supostamente "normal"; também não são compreendidos apenas como "mecanismos de defesa"; mas como um contramovimento, com o qual afinal se pode simpatizar, contra uma constituição completamente contraposta do ser, para a qual atinamos quando temos diante de nós em sua forma caricatural aquele positivo do qual, geralmente, o comportamento histérico é apartado. A representação de papéis do histérico apresenta-se então como "contra-ataque" contra uma concepção de vida orientada excessivamente por autenticidade, identidade do ser, "constituição de identidade", semelhante àquela que Kraus (1977), na trilha de Tellenbach (1976), elaborou para o Typus melancholicus. Certamente, isso necessitaria ainda de verificação e diferenciação críticas, pois existe apenas uma polaridade parcial, não contínua, entre estrutura melancólica e histérica. Nesse contexto, a procura de modo geral por uma positividade no negativo (quer dizer, no que prejudica patologicamente) é decisiva. Uma tal modulação do compreender possibilita um se-sentir-acolhido mais profundo do paciente, que de regra já se identifica num certo sentido com seu "desvio". Com isso, essa abordagem possibilita, ao mesmo tempo, um vínculo de trabalho mais confiável, ao dar para

\footnotetext{
${ }^{30}$ Não podemos tratar aqui da vasta literatura sobre o problema da criatividade.

${ }^{31}$ Cf. também Petrilowitsch (1970); Thiemann e Zahn (1973); Baum (1978). A compreensão desses autores sobre dialética não é, contudo, idêntica à que defendemos aqui.
} 
o paciente aquele sentimento de ser aceito, com base no qual ele é mais capaz de se questionar e se permitir novas possibilidades de autorrealização, sem precisar temer uma perda de si.

No fundo, essa tarefa se coloca não de outra maneira, mas de forma acentuada, também em relação aos pacientes esquizofrênicos. Sem identificação parcial, sem a pergunta "contra o que" se dirige, afinal, aquilo que experienciamos, na relação com o doente, como um outro estar-no-mundo - isto é, sem a pergunta sobre a positividade do negativo -, praticamente não achamos um acesso adequado a ele. Esse acesso é mais difícil do que com outros pacientes. Ele é significativamente facilitado através de uma abordagem dialética. Esta nos leva a que primeiro questionemos não apenas o doente, mas, através dele, ao mesmo tempo, a nós mesmos. Não enquanto atitude, mas, na medida em isso nos é possível, de tal maneira que, através dele, nós nos deixamos colocar em movimento a respeito dos pressupostos, a respeito do que é fundamentalmente óbvio em nossa existência. Se o paciente nota isso, então, não raramente, pode-se construir uma outra forma de vínculo de trabalho terapêutico, diferente da que é possível apenas com a boa vontade do terapeuta. Esse vínculo carrega, contudo, um caráter bilateral diferente [165] do vínculo com pacientes neuróticos. Ele se enraíza mais profundamente, mas, ao mesmo tempo, é significativamente mais frágil. Ele exige do terapeuta um maior empenho, frequentemente maior do que ele é capaz (Benedetti, 1975; Müller, 1976).

O que tentamos trazer para diante de nós com a ajuda da abordagem dialética é aquilo que é "dado" ao paciente. Trata-se de ter isso presente, para, partindo daí, ganhar uma melhor compreensão das tentativas de lidar com a realidade mais ou menos malsucedidas que percebemos em seu comportamento. Não podemos ser justos com o doente se não avaliamos corretamente o tamanho da tarefa que se coloca para ele (por exemplo, a integração de tendências altamente contraditórias) ${ }^{32}$.

Desse ponto de vista, especialmente a "fraqueza do eu",33 de pacientes esquizofrênicos precisa de uma análise mais diferenciada. Ela não deve ser colocada como grandeza absoluta, mas como grandeza relativa a cada tarefa a ser resolvida. Esta é, nos esquizofrênicos tardios, frequentemente mais complexa e difícil do que aquela diante da qual se veem outras pessoas. Quando a organização do eu (a força de integração de uma existência humana) não está à sua altura, isso não depende exclusivamente de uma fraqueza do eu preestabelecida (por exemplo, geneticamente determinada), mas pode derivar também da "força explosiva" do que é dado a alguém (Aufgegebenen), isto é, da divergência de numerosos momentos da situação interna e externa de um paciente (isto é, daquilo que é exigido dele e daquilo que ele exige de si).

Se podemos nos perguntar, quanto a depressivos endógenos, sobre a possibilidade de o verdadeiro mal neles ser uma insuficiência de estruturação dialética de sua relação com o mundo e consigo, então impõe-se a pergunta contrária quanto à maior parte dos pacientes esquizofrênicos ${ }^{34}$. A investigação do

\footnotetext{
32 Até agora não foi possível separar qualitativamente formas de cisão interna, tendência à ambivalência e ambitendência em pessoas que depois se tornarão esquizofrênicas daquelas que também podem ser observadas em pessoas que não se tornarão esquizofrênicas. Cf. sobre esse complexo de perguntas Bleuler (1972), Garmezt (1978).

${ }^{33}$ Remeta-se aqui ao conceito de egopatia da pesquisa americana sobre esquizofrenia.

${ }^{34}$ Quanto à distinção entre um excesso ou uma falta de estruturação dialética pode-se invocar Gabel (1967). Ele falou, contudo, sobre uma falta em relação à esquizofrenia, o que também parece consistente com o delírio sistematizado e a tendência observável em esquizofrênicos a "alternativas rígidas" (Binswanger, 1957), mas não com a dinâmica em fase inicial. Quanto a ela, é legítima a hipótese de que justamente uma sensibilidade especial quanto a estruturas dialéticas leva a uma desdialetização contrarregulatória da referência a si e ao mundo.
} 
alcance da perspectiva dialética na psicopatologia leva também aqui à pergunta pela estruturação dialética do objeto dessa perspectiva.

Existe algo como um excesso de estruturação dialética na existência humana (de início, independentemente da pergunta quanto àquela ser vista mais sob aspectos biológicos ou biográficos), um excesso que, em uma manifestação acentuada, cedo ou tarde resulta em uma psicose esquizofrênica, e, em manifestação mais modesta, talvez deixe abertas outras alternativas? Devemos reconhecer que não dispomos ainda dos métodos adequados para [166] poder responder essa pergunta de modo conclusivo. Mas há não poucas experiências que falam a favor dessa suposição. Ela não é nova.

A tentativa de compreender dialeticamente "insanidade" (Wahnsinn), "loucura" (Verrücktheit), "doenças do espírito" (aquilo que hoje chamamos de "esquizofrenia") remonta ao mais antigo costume da humanidade. Sem tratar das tradições oriental e grega, lembremos apenas de uma antiga saga celta (Rodenberg, 1857): dizia-se que, nas montanhas de Wales, naquela altura onde se sobe para Snowdon, havia uma grande pedra negra com o nome "Arddu". Quando duas pessoas dormiram certa noite sobre ela - assim diz o costume -, no romper do dia, logo que o primeiro raio do sol matinal caiu sobre a pedra, não se podia prever qual dos dois foi atingido pela loucura. A partir daí seria possível traçar uma linha até aquela frase de J. Joyce sobre seu Ulisses: "Tanto faz, foi terrivelmente ousado esse livro. Uma folha transparente o separa da loucura" (Gilbert, 1960). Na mesma direção apontam as interpretações (retomando as tradições gregas) de Hölderlin da psicose que se aproximava (como o avesso de sua missão poética).

Também no cotidiano clínico nós encontramos, não raramente, pacientes que compreendem sua psicose dessa ou de maneira semelhante. Eles se sentem destacados (em relação à existência média burguesa) através dela: "Ascender do eu convencional para a busca esquizofrênica por um eu 'mais autêntico' é vivenciado de modo ambíguo" (Bleuler, 1972, p. 619). Querer ver aqui apenas a realização psicótica de um desejo não seria suficiente. Fala contra isso a impressão que se pode obter na relação imediata com esquizofrênicos. Parece antes mais provável que haja, em muitas psicoses, um núcleo que se subtrai às categorias de deficiência. A partir daí, tem-se outra visão sobre algo do que se conhece por "delírio de grandeza" e "ausência de crítica da doença". É, contudo, extremamente raro que uma psicose libere a criatividade remanescente, por assim dizer, guie para uma saúde nova "superior". Na literatura mais antiga, podemos remeter ao caso clínico de Schwab (1919). Mas a raridade de tais ocorrências faz parecer leviano enaltecer a psicose esquizofrênica como "viagem para outra terra", para não dizer quase como um tipo de remédio para nossa sociedade congelada em estratégias de adaptação, tal como fez Laing (1969). Ainda não foi comprovado que se possa provocar, mais do que em casos específicos controversos, uma tal guinada através da psicoterapia ou socioterapia [167]. Quando ocorre, trata-se de um acontecimento tocante.

Não obstante, nós nos deparamos, também no exemplo da esquizofrenia, com o problema das relações entre criatividade e transtornos psíquicos. Sobre isso há uma ampla bibliografia. As opiniões são divididas. Deve-se ter em conta, ao responder essa pergunta (isso já foi enfatizado), o que em cada caso designamos como "psicose": a invasão de uma estrutura de existência juntamente com a confrontação com um totalmente outro, paradoxal (no sentido de uma situação-limite), ou somente o resultado dessa invasão na forma de determinadas informações de defesa, mecanismos, bloqueios, formações substitutivas (por exemplo, sistemas de delírio) ou simplesmente deficiência. A partir disso, podem ser em parte explicados os diferentes posicionamentos. 
Benedetti (1975, p. 84) formula que "a contraditoriedade da existência, na qual se despedaça o eu esquizofrênico fraco, não é em si um momento patológico, mas apenas um momento impactante"; também que "não a doença em si, mas o sofrimento que resulta do vivenciar da doença" poderia aumentar a criatividade, por exemplo, a mensagem de um escritor. No entanto, permanece questionável se uma "contraditoriedade da existência" já não tem ela mesma, em grande medida, algo a ver com a esquizofrenia; quer dizer, se essa "contraditoriedade" pode assumir qualquer grau, sem que uma pessoa corra o risco de adoecer esquizofrenicamente; além disso, se "o sofrimento, que resulta do vivenciar da doença", pode ser tão claramente diferenciado desta última, como seria de esperar a partir dessa formulação.

As relações da perspectiva dialética com a esquizofrenia não se esgotam no fato de que se pergunta, aqui como em outras doenças, pela positividade possível do negativo. As transformações da vida anímica que nós designamos como "esquizofrênicas" mostram elas mesmas algo dialético, desde que as entendamos como "sim $e$ não", a abertura e, ao mesmo tempo, a sensibilidade para aquele "é e não é", para todo o questionamento da sentença da contradição. Não por acaso, Beuler (1972) ressaltou que a ambivalência é um transtorno fundamental muito característico da esquizofrenia, mesmo que não seja precisamente delimitado e nem mesmo possa ser.

Também pertencem a esse contexto a sensibilidade e a sensitividade de esquizofrênicos em relação a situações double-bind. De fato, ainda não foi comprovado se situações double-bind ocorrem significativamente mais nas famílias de esquizofrênicos do que naquelas [168] de saudáveis e neuróticos. Seu significado patogênico é controverso ${ }^{35}$. Contudo, pode-se comprovar satisfatoriamente através da experiência clínica que as situações double-bind desempenham um papel especial em muitos esquizofrênicos e que estes mostram uma sensibilidade particular em relação a elas. No entanto, a observação de que, para eles, parece existir tanto uma afinidade quanto uma vulnerabilidade específicas levanta problemas significativos. Não podemos aqui investigar os problemas associados a isso. Esta tarefa será reservada para um trabalho separado. Contudo, não se pode deixar de mencionar o fato interessante de que, no estudo clássico de Bateson et al. (1969), a situação double-bind é elucidada a partir da maneira como um mestre zen se relaciona com seus discípulos. De maneira notável, tanto um koan, como as instruções práticas do mestre zen são estruturados dialeticamente (quando aqui entendemos por "dialeticamente" apenas um ignorar propositado da "sentença da contradição" e da "sentença do terceiro excluído"). Isso significa que situações double-bind, como é enfatizado na literatura recente (Wynne 1976), evidentemente não precisam ter em todo caso necessariamente um efeito patogênico. Com elas se deve suscitar no zen, propositadamente, uma transformação de consciência não patológica. De acordo com informações de um colega japonês, provoca-se assim ocasionalmente psicoses. Seja aqui mencionado que o grupo de trabalho em torno de Watzlawick (1979) abordou de maneira mais notável o problema do efeito psicodinâmico de paradoxos e situações paradoxais. Na psicoterapia, o trabalho com técnicas "paradoxais" tem ganhado cada vez mais relevância (Palazzoli et al., 1977; Titze, 1988; Weeks, 1977).

Material pertinente para esse complexo de perguntas foi fornecido a partir de um lado totalmente diferente: pela pesquisa comportamental (Ploog, 1973). De modo experimental, a sensibilidade quanto à "minimização alternativa" pode ser testada em animais. Os animais são postos em situações que não provocam claramente atenção ou afastamento, mas que são ambíguas nesse ponto; ao menos,

\footnotetext{
${ }^{35} \mathrm{Cf}$. sobre o que segue o panorama de Angermeyer (1978) bem como Wynne (1976) sobre os desenvolvimentos recentes do conceito de double-bind. Sobre a relação criativa (umgag) com a ambiguidade, cf. Devereuz (1966) e "Seven types of ambiguity" de Empson (1964).
} 
aproximam abertamente uma da outra possibilidades de reação alternativas. Essa "minimização alternativa" não pode ser igualada, contudo, a uma "dialetização" do comportamento ambiental, ou melhor, do sistema de estímulo e reação. No entanto, a "dialetização" da relação com o que vem ao encontro é uma maneira através da qual se pode realizar a "minimização alternativa". Com todas as reservas quanto à transponibilidade da observação de comportamento animal para [169] o comportamento humano, pode-se, a partir daqui, traçar uma linha que se liga às pesquisas que têm por objeto a tolerância ou intolerância do ser humano à ambiguidade (veja acima). Como se sabe, há diferenças características naqueles que são predispostos às várias doenças psíquicas. Nesse contexto, deveriam ser também mencionadas as pesquisas da psicologia da Gestalt (fenômenos Kipp) e experiências de testes psicológicos (Testpsychologie) (interpretações negativas no teste de Rorschach).

Nesse contexto, não espanta que, assim como há tentativas de compreender dialeticamente os esquizofrênicos, também tenha havido tentativas de, inversamente, desmascarar o pensamento dialético como um pensamento disfarçadamente esquizofrênico. Treher (1959) acreditava poder comprovar, com um vasto material, que Hegel - referindo-se ao fato da doença de sua irmã - teria sido, na verdade, um esquizofrênico. Nesse caso, provavelmente se trata de um erro de diagnóstico (cf. quanto a isso também Drüe, 1976). Mas, com isso, o problema não está resolvido. De acordo com Heston (1966) e Garmezy (1978), encontram-se entre os parentes de esquizofrênicos, com uma frequência superior à média, personalidades criativas, que extrapolam de alguma maneira os parâmetros convencionais. Também foi ocasionalmente expressa a hipótese complementar de que os esquizofrênicos estariam super-representados entre os parentes de personalidades criativas. Para comprová-lo de modo irrefutável, seria necessário, contudo, primeiramente definir de forma mais precisa o que se deve entender por "criatividade". Parece razoável supor que um acúmulo de casos de esquizofrenia se deixa comprovar apenas no parentesco daqueles artistas, escritores e demais criativos cujas obras se caracterizam pelo domínio de uma cisão particularmente profunda. Pode-se esperar mais esclarecimentos das investigações da psicologia do desenvolvimento sobre a ontogênese das operações dialéticas (Rychçak, 1976; Riegel, 1978). Também aqui, dialética enquanto método de pesquisa e enquanto objeto de pesquisa se relaciona de maneira estreita e ainda insuficientemente esclarecida. Seria o caso de se remeter à solução indicada acima, que conecta a perspectiva epistemológico-lógica com a psicodinâmica.

Tudo isso mostra que nossa pergunta, "qual o alcance da perspectiva dialética na psiquiatria?", tem particular pungência com relação à esquizofrenia. Afinal, trata-se aqui de se perguntar se o presente transtorno não tem ele mesmo algo a ver com o dialético no interior do processo antropológico; por exemplo, no sentido de que um momento dialético, que por si só constitui um móvel do desenvolvimento, rompe aqui a estrutura [170] da existência humana. No prefácio à segunda edição de La conscience, Ey (1969) se pronunciou a respeito: de fato, a psicose esquizofrênica teria algo a ver com a cisão interna, quer dizer, com o dialético da existência humana; mas de forma alguma poderia ser suficientemente entendida a partir disso. Algo análogo se encontra sugerido em Benedetti (1975). Não se pode dizer no presente algo vinculatório a esse respeito. Para tanto, não bastam nossas visões sobre o ambíguo na natureza humana. A despeito disso, pode-se perguntar (presumindo-se que algo de acertado subjaz ao entendimento antropológico do homem como um "ser de carências"36): quais são, por um lado, as "carências" do homem que significam simples deficiência, quais, por outro, indicam um processo

\footnotetext{
${ }^{36}$ Não pensamos aqui em uma interpretação biológica da "carência", mas, antes, em uma antropológica, do tipo que podemos encontrar, por exemplo, em Wyss (1973, 1976).
} 
ainda não concluído de evolução do homem? Nem todas "carências" deveriam ser hipercompensáveis; apenas muito poucas, provavelmente, em comparação com a abundância dos impasses.

Por mais que muitos fenômenos da esquizofrenia remetam a uma regressão - tanto filogenética, quanto ontogenética -, também se pode interpretar algumas observações igualmente no sentido de uma progressão patológica (cf. fenômenos de insegurança do instinto quanto à hipótese de sobredomesticação). Mesmo sem nos permitirmos mais especulações, fica claro que a questão aqui abordada sobre o alcance da perspectiva dialética na psiquiatria não deve ser vista de modo independente da questão mais geral sobre a evolução e possível metamorfose da existência humana como um todo.

$\mathrm{Na}$ psicoterapia, sobretudo naquela de esquizofrênicos, nós seremos - queiramos ou não constantemente confrontados com essa pergunta antropológica. Mesmo ali, onde nós não o fazemos de modo consciente, nossas respostas a tais questões moldam a maneira como nos relacionamos com nossos pacientes, como nos postamos diante deles, como tentamos ajudá-los. 


\section{Referências}

Adorno, T. W. (1966). Negative Dialektik. Frankfurt: Suhrkamp.

Adorno, T..W. (1971). Drei Studien zu Hegel. In Gesammelte Schriften (Bd. 5). Frankfurt: Suhrkamp.

Albert, H. (1971). Erkenntnis, Interesse und Gesellschaft Zur Kritik des dialektischen Denkens. In H. Albert, Konstruktion und Kritik: Aufsätze zur Philosophie des kritischen Rationalismus. Hamburg: Hoffmann \& Campe.S

Angermeyer, M. (1978). 20 jahre Double-Bind: Versuch einer Bilanz. Psychiatrische Praxis, 5, 106-117.

Ansbacher, H. L. (1977). Die Rolle der Dialektik in der Adlerschen Psychologie. In R. Kausen, \& F. Mohr (Hrsg.), Beiträge zur Individualpsychologie (pp. 16-24). München: Reinhardt.

Barion, J. (1960). Dialektik der Natur und Geschichte. In J. Derbolov, \& F. Nicolin (Hrsg.), Erkenntnis und Verantwortung: Festschrift für Theodor Litt (pp. 91-104). Düsseldorf: Schwarm.

Barron, F, (1969). Creative person and creative process. New York: Holt, Rinehart \& Winston.

Bateson, G. et al. (1969). Auf dem Weg zu einer Schizophrenie-Theorie, in: Kulen-kampff, C. (Hrsg.), Schizophrenie und Familie (pp. 11-43). Frankfurt: Suhrkamp.

Baum, H. (1978). Zum Dialektischen im ,Erfolg” und „,Misserfolg” in der Psychotherapie. Bern: Huber.

Becker, W. (1969). Hegels Begriff der Dialektik und das Prinzip des Idealismus: Zur systematischen Kritik der logischen und der phänomenologischen Dialektik. Stuttgart: Kohlhammer.

Becker, W. (1970). Idealistische und marxistische Dialektik. Stuttgart: Kohlhammer. Benedetti, G. (1962). Dialektische Begriffspaare in der Psychotherapie. Jahrbuch Psychol. Psychother. med. Anthropol. 9 pp. 304315.

Benedetti, G. (1975). Psychiatrische Aspekte des Schöpferischen und schöpferische Aspekte der Psychiatrie. Göttingen: Vandenhoeck \& Rupprecht.

Benedetti, G. (1977). Identifizierung und Identitätsbildung in der individuellen Psychotherapie bei Schizophrenen. Zeitschrift Fur Klinische Psychologie Und Psychotherapie, 25, 219-270.

Berner, P., \& Gabriel, E. (1977). Krisenintervention in der Psychiatrie. Psychiatria Clinica, 10, 5-172.

Binswanger, L. (1947). Vorträge und Aufsätze. Bern: Francke.

Binswanger, L. (1957). Schizophrenie. Pfullingen: Neske.

Binswanger, L. (1964). Grundformen und Erkenntnis menschlichen Daseins. Basel: Reinhardt.

Blankenburg, W. (1958). Daseinsanalytische Studie über einen Fall paranoider Schizophrenie. Schw. Arch. Neurol. Psychiat. 81, 9-105.

Blankenburg, W. (1974). Hysterie in anthropologischer Sicht. Praxis der Psychotherapie, 19, 262-273.

Blankenburg, W. (1975). Was heißt „Erfahrung"? In A. Métraux, \& C. F. Graumann (Hrsg.), Versuche und Erfahrung (pp.9-20). Bern/: Huber.

Blankenburg, W. (1987a). Grundlagenprobleme der Psychopathologie. Nervenarzt, 49, 140-146.

Blankenburg, W. (1978b). Was heißt anthropologische Psychiatrie? In A. Kraus (Hrsg.), Leib, Geist, Geschichte (pp. 15-28). Heidelberg: Hüthig. 
Blankenburg, W. (1979).Psychiatrie und Philosophie. In: K. P. Kisker, et al. Psychiatrie der Gegenwart (pp. 827-875). Berlin: Springer.

Blankenburg, W. (1981). A dialectical conception of anthropological proportions. In A. J. J. Koning, \& F. A. Janner (Eds.), Phenomenological psychiatry. London: AcademicPress.

Blankenburg, W. (1981). Nomothetische und idiographische Methodik in der Psychiatrie. Schweizer Archiv für Neurologie, Neurochirurgie und Psychiatrie, 128, 13-20.

Blankenburg, W. (1980). Phenomenology and Psychopathology. Journal of Phenomenological Pschychology, $11,50-78$.

Bleuler, M. (1972). Die schizophrenen Geistesstörungen im Lichte langjähriger Kranken- und Familiengeschichten. Stuttgart: Thieme.

Bloch, E. (1977). Gesamtausgabe (Bd. 13). Frankfurt: Suhrkamp.

Boeder, H. (1968). Der Ursprung der „Dialektik" in der Theorie des „Seienden": Parmenides und Zenon. Studium Generale, 21, 184-202.

Brand, G (1978). Zur Phänomenologie der Intersubjektivität. Phänomenologische Forschungen, 6/7, 28-117.

Bubner, R. (1973). Dialektik und Wissenschaft. Frankfurt: Suhrkamp.

Bubner, R., Cramer, K., \& Wiehl, R. (Hrsg.). Hermeneutik und Dialektik. Tübingen: Mohr.

Callieri, B., Castellani, A. \& Vincentis, G. (1972). Lineamento di una Psychopathologica Fenomenologica. Roma: II Pensiero Scientifico.

Canguilhem, G. (1972). Le normal et le pathologogique. Paris: Presses Urtiversitaires de France.

Castilla del Pino, C. (1966). Un estudio sobre la depresión: Fundamento anthropologica dialectica. Barcelona: Peninsola.

Conrad, K. (1963). Gestaltanalyse und Daseinsanalytik. Zugleich Bemerkung zu dem voranstehenden Artikel „Problem der abnormen Krise" von C. Kulenkampff, in: Straus, E., Zutt, J. und Sattes, H. (Hrsg.), Die Wahnwelten. Fankfurt a.M.: Akademische Verlagsanstalt 1963, S. 288-301. Schlusswort zur Diskussion über das „Problem der abnormen Krise", in: ebd. S.312-315. (Erste Veröffentlichung in: Nervenarzt 30 (1959) S. 405-410 und 463-464.)

Coulter, J. (1973). Approaches to insanity. London: Robertson.

Daele, L. D. (1975). Ego development in dialectical perspective. Human Development, 18, 129-142.

Davids, A. (1955). Some personality and intellectual correlates of intolerance of ambiguity. Journal of Abnormal Psychology, 51, 415-420.

Davids, A. (1963). Psychodynamic and sociocultural factors related to intolerance of ambiguity. In R. W. White (Ed.), The study of lives (pp. 160-177). Englewood Cliffs: Prentice Hall.

Devereux, G. (1966). The exploitation of ambiguity in Pindaros. Rheinisches Museum für Philologie, 109, 289298.

Diemer, A. (1966). Zur Grundlegung einer Philosophie der Medizin. Homburg: Chemiewerk.

Diemer, A. (1976). Elementarkurs Philosophie: Dialektit. Düsseldorf: Econ. 
Döner, K. (1979). Psychiatrie und Gesellschaftstheorien. In: K. P. Kisker, Psychiatrie der Gegenwart (Bd. 1/1, pp. 7710809). Berlin.

Drüe, H. (1976). Psychologie aus dem Begriff. Berlin: de Gruyter.

Empson, W. (1964). Seven types of ambiguity. New York: Harper \& Row.

Ey, H. (1969). La conscience. Paris: Presses de Universitaires de France.

Ey, H. (1975). La psychose et lex psychotique. Evol. psychiat. 40, 103-116.

Fink. E. (1975). Phänomenologie und Dialektik. In E. Fink, Nähe und Distanz (pp. 228-249). Freiburg: Alber.

Flach, F. F. (1974). The secret strength of depression. Philadelphia: Lippincott.

Flach, W. (1959). Negation und Andersheit. München: Reinhardt.

Foudraine, J. (1976). Wer ist aus Holz? München: Neue Wege der Psychiatrie.

Fränkel-Brunswik, E. (1948). Intolerance of ambiguity as an emotional and perceptual variable. Journal of Personality, 18, 108-143.

Freud, A. (1968). Das Ich und die Abwehrmechanismen. München: Kindler.

Freud, S. (1972). Jenseits des Lustprinzips. Frankfurt: Fischer.

Funke, G. (1960). Phänomenologisches und dialektisches Bewußtsein. In J. Derbolov, F. Nicolin (Hrsg.), Erkenntnis und Verantwortung: Festschrift für Theodor Litt (pp. 63-90). Düsseldorf: Schwann.

Gabel, J. (1962)., La fausse conscience: essai sur la réification. Paris: Les Editions de Minuit .

Gadamer, H.-G. (1964). Philosophische Bemerkungen zum Problem der Intelligenz. Nervenarzt, 35, 280-286.

Gadamer, H.-G. (1971). Hegels Dialektik: Fünf hermeneutische Studien. Tübingen: Mohr.

Garmezy, N. (1978). Vulnerable and invulnerable children: theory, research and intervention. Chicago: American Psychological Association.

Gastaut, H. (1979). L'involontaire contribution de Fiodor Mikhailovitsch Dostoijvevski a la symptomatologie et au pronostic de l'épilepsie. Evol. Psychiatrique, 44, 215-219.

Gilber, S. (1960). Das Rätsel des Ulysses: Eine Studie. Zürich: Rhein.

Giorgi, A. (1970). Psychology as a human science. New York: Harper \& Row.

Glaser, J. (1979). Das dialektische Denken und das natürliche Bewusstsein. In: Lorenz, K. (Hrsg.), Konstruktionen versus Positionen. Bd. II: Allgemeine Wissenschaftstheorie. (pp. 333-347). Berlin: de Gruyter..

Glatzel, J. (1975). Antipsychiatrie. Stuttgart: Fischer.

Gnädinger, H. W. (1976). Gegensatz als Prinzip des Psychischen bei Sigmund Freud. Zürich: Unveröff. Diss.

Goldmann, L (1966). Dialektische Untersuchungen. Neuwied: Luchterhand.

Grimm, J. (197). Begegnung und Vergegnung. Heidelberg: Unveröff. Diss.

Hegel, G. W. F. (1958). Sämtliche Werke: Jubiläumsausgabe. Stuttgart: Fromanns.

Heidegger, M. (1927). Sein und Zeit. Halle: Niemeyer. 
Heiss, R. (1959). Wesen und Form der Dialektik. Köln: Kiepenheuer \& Witsch.

Heraklit, Fragmente. (1922). In D. Diels, D. (Hrsg.), Die Fragmente der Vorsokratiker (pp. 67-113). Berlin: Weitmann.

Heston, L. (1966). Psychiatric disorders in foster home reared children of schizophrenic mothers. British Journal of Psychiatry, 112, 819-825.

Jung, H. Y. (1977). The concept of the dialectic in Hegel, Marx and Merleau-Ponty. Jounal of the British Society for Phenomenology, 8, 56-58.

Kafka, J. S. (1977). Zum Problem der Realität, Reflexionem über Objektkonstanz, Ambiguität, Paradox und Zeit. Psyche, 31, 712-731.

Kanthack, K. (1968). Das Wesen der Dialektik im Lichte Martin Heideggers. Studium Generale, 21, 538-554.

Kimmich, H. Anthropologie und Menschlichkeit. Der Beitrag Ludwig Binswangers zur Humanisierung der Psychiatrie. Unveröff. Diss. Göttingen 1978.

Kisker, K. P. Antipsychiatrie. In Psychiatrie der Gegenwart (pp. 811-825). Berlin: Springer.

Kisker, K. P. (1970a). Dialogik der Verrücktheit. Ein Versuch an den Grenzen der Anthropologie. Den Haag: Nijhoff.

Kisker, K. P. (1969). Die Phänomenologie der Intersubjektivität. In C. F. Graumann (Hrsg.), Hb. der Psychologie. Göttingen: Hogrefe.

Kisker, K. P. (1970). Positives in der Verrücktheit. In Kreativität in der Psychose (pp. 43-51). Hannover: Medizinische Hochschule.

Köchler, H. (1977). Dialectical Conception of Self-Determination. In Tymieniecka, A. T. (Ed.). The self and the other: the irreducible element in man (62-80). Dodrecht: Reidel.

Kopper, J. (1957). Die Dialektik im französischen Denken der Gegenwart. Zeitschrift für philosophische Forschung, 11, 80-91.

Koselleck, R., Tsouyopoulos, N., \& Schönpflug, U. In J Ritter, \& K. Gründer (Hrsg.). (1976). Historisches Wörterbuch der Philosophie (pp. 1235-12450). Basel: Schwabe 1976, S. 1235-1245.

Kraus, A. (1977). Sozialverhalten und Psychose Manisch-Depressiver. Stuttgart: Enke.

Kruks, S. (1976). Merleau-Ponty, Elege! and die Dialectic. Joumal of die British Society for Phenomenology, 7, 96-110.

Kubie, L. S. (1976). Die Wechselwirkung zwischen schöpferischen und neurotogenen Vorgängen, in: Mitscherlich, A. (Hrsg.), Pathographie I, Schriftsteller und Psychoanalyse. Frankfurt a.M.: Suhrkamp 1972, S. 1-45.

Kubie, L. S. (1966). Psychoanalyse und Genie: Der schöpferische Prozeß. Reinbek: Rowohlt.

Kulenkampff, A. (1970). Antinomie und Dialektik Stuttgart: Kohlhammer.

Kulenkampff, C. (1963). Zum Problem der abnormen Krise in der Psychiatrie. In E. Straus, \& J. Zutt (Hrsg.), Die Wahnwelten (pp. 258-287). Frankfurt: Akademische Verlagsgesellschaft.

Laing, R. D. (1976). The Politics of Experience. London: Penguin.

Landgrebe, L. (1960). Das Problem der Dialektik. In I. Fetscher, Marxismusstudien (pp. 1-65). Tübingen: Mohr. 
Lang, H. (1978). Geschichtlichkeit des Daseins oder Entwicklung des Soma? Überlegungen zum wissenschaftlichen Standort der Psychoanalyse. In A. Kraus (Hrsg.), Leib, Geist, Geschichte: Brennpunkte anthropologischer Psychiatrie (pp. 121-138). Heidelberg: Hüthig.

Lechler, L. (1976). Gesund ist, wer noch krank werden kann. In H. Rein (Hrsg.), Dienstgespräche (pp. 63-94). Stuttgart: Kreuz.

Malantschuk, G. (1970). Søren Kierkegaard und das kollaterale Denken. Zeitschrift für philosophische Forschung, 24, 1-16.

Marcuse, H. (1975). Hegels Ontologie und die Theorie der Geschichtlichkeit. Frankfurt: Klostermann.

Meacham, J. A., \& Riegel, K. F. (1979). Dialektische Perspektion in Piagets Theorie, In G. Steiner (Hrsg.), Die Psychologie des 20. Jahrhunderts. Zürich: Kindler.

Meadows, P. (1994). The Dialectic of the Situation. Philosophy and Phenomenological Research, 5, 354-365.

Müller, C. (1976). Psychotherapie und Soziotherapie der Schizophrenen. In G. Hubert. (Hrsg.), Therapie, Rehabilitation und Prävention schizophrener Erkrankungen (pp. 289-298). Stuttgart: Schattauer.

Müller-Eckardt, H. (1954). Die Krankheit nicht krank sein zu können. Stuttgart: Klett.

Nauta, L. W. (1968). Dialektik bei Sartre. Studium Generale, 21, 591-607.

O'Connor, P. (1952). Ethnocentrism, "Intolerance of Ambiguity"; and Abstract Reasoning Ability. Journal of Abnormal and Social Psychology, 47, 526-530.

Orth, E. W. (1977). Anthropologie und Intersubjektivität. Phänomenologische Forschungen, 4, 103-129.

Palazzoli, M. S., Boscolo, L., Cecchin, G., \& Prata, G. (1977). Paradoxon und Gegenparadoxon. Stuttgart: Klett.

Perelman, C. (1979). Dialectique et Dialogue. In Bubner et al. (pp. 77-84).

Petersen, U. (1980). Die logische Grundlegung der Dialektik. München: Fink.

Petrilowitsch, N. (1970). Dialektische Psychotherapie. Zugleich ein Beitrag zur Psycho-pathologie von Neid und Missgunst. Psychiatria Clinica, 3, 192-204.

Ploog, D. (1973). Verhaltensforschung und Psychiatrie In K. P. Kisker, et al., Psychiatrie der Gegenwart (pp. 291-443). Berlin: Springer.

Popper, K. R. (1976). Was ist Dialektik? In E. Topitsch (hsrg.), Logik der Sozialwissenschaften (pp. 262-290).

Rabil Jr., A. (1967). Merleau-Ponty. Existentialist of the social world. New York: Columbia University Press.

Rademacher, H. (1973). Dialektik. In H. Krings, et al. (Hrsg.), Handbuch philosophischer Grundbegriffe (pp. 289-309). München: Kösel.

Reiter, L., \& Strotzka. H. (1977). Der Begriff der Krise. Psychiatria Clinica, 10, 7-26.

Rickert, E. (1921). Der Gegenstand der Erkenntnis. Tübingen: Mohr.

Rickert, E. (1924). Das Eine, die Einheit und das Eins. Tübingen: Mohr.

Riegel K. P. (Hrsg.). (1978). Zur Ontogenese dialektischer Operationen. Frankfurt: Suhrkamp.

Ritter, J. (Hrsg.). (1972). Historisches Wörterbuch der Philosophie. Basel: Schwabe.

Röd, W. (1974). Dialektische Philosophie der Neuzeit. München: Beck. 
Rodenberg, J. (1956). Ein Herbst in Wales. In G. Massenbach (Hrsg.), Märchen der Völker (pp. 120-123). Baden-Baden: Holle.

Rychlak, J. F. (Hrsg.). (1976). Dialectic. humanistic rationale for behavior and development. Basel: Karger.

Schäfer, M. L. (1980). Das Problem der Intersubjektivität. In U. H. Peters (Hrsg.), Die Psychologie des 20. Jahrhunderts (pp. 63-77). Zürich: Kindler.

Schölmerich, P. (1978). Zum Begriff der Krise im individuellen Krankheitsablauf. In M. Steinhausen (Hrsg.), Grenzen der Medizin. Medizin im Wandel (pp. 107-113). Heidelberg: Huthig.

Schroyer, T. Die dialektischen Grundlagen der kritischen Theorie. In W. Dallmeyer (Hrsg.), Materialien zu Habermas' „Erkenntnis und Interesse“ (pp. 41-70). Frankfurt: Suhrkamp.

Schwab, F. (1919). Selbstschilderung eines Falles von schizophrener Psychose. Zeitschrift für die gesamte Neurologie und Psychiatrie, 44, 3-20.

Schweppenhäuser, H. (1973). Negative Dialektik und die Ideen der Versöhnung. Stuttgart: Kohlhammer.

Seel, G. (1971). Sartres Dialektik. Bonn: Grundmann.

Seifert, F. (1935). ldeendialektik und Lebensdialektik. In Psychologischer Club, Zürich (Hrsg.), Die kulturelle Bedeutung der komplexen Psychologie. Festschrift zum 60. Geburtstag von C. G. Jung (pp. 237-270). Berlin: Springer.

Siirala, M. (1963). Die Schizophrenie das Einzelnen und der Allgemeinheit. Göttingen: Vandenhoeck \& Rupprecht.

Stierlin, H. (1975). Von der Psychoanalyse zur Familientherapie. Stuttgart: Klett.

Strasser, S. (1961). Intuition und Dialektik in der Philosophie Edmund Husserls. In E. Husserl, Phaenomenologica (Vol. 4, pp. 148-153). Den Haag: Nijhoff.

Tatossion, A. (1979). Phénoménologie da psychoses. Rapport de psychiatrie. Paris: Masson.

Taubes, J. (1970). Dialectiques et Psychoanalyse. Notes pour une interprétation philosophique de la méthode psychoanalytique. In J. Taubes, Critique sociologique et critique psychoanalytique. Bruxelles: Editions de l'Institute de Sociologie Université.

Tellenbach, H. (1976). Melancholie. Berlin: Springer.

Theunissen, M. (1968). Der Andere. Berlin: de Gruyter.

Theunissen, M. (1980). Sein und Schein. Die kritische Funktion der Hegelschen Logik. Frankfurt: Suhrkamp.

Theunissen, M., \& Greve, W. (1979). Materialien zur Philosophie. Frankfurt: Suhrkamp.

Thiemann, E., \& Zahn, E. (1973). Dialektische Strukturen bei psychischen und psychopathologischen Prozessen. Nervenarzt, 44, 330-331.

Titze, M. (1977). „Paradoxe Intention" eine Individualpsychologische Technik. Z. F. Lndividualpsych, 2, 103-112.

Topitsch, E. (Hrsg.). (1976). Logik der Sozialwissenschaften. Köln: Kiepenheuer \& Witsch.

Treher,W. (1959). Hegels Geisteskrankheit oder das verborgene Gesicht der Geschichte. Emmendigen: Selbstverlag.

Waelhans, A. (1951). Une Philosophie de l'Ambiguité. Paris: Nauwelaerts. 
Waldenfels, B. (1970). Im Zwischenreich des Dialogs. Den Haag Nijhoff.

Waldenfels, B., Broekman, J. M., \& Pazanin, A. (Hrsg.). (1977). Phänomenologie und Marxismus. Frankfurt: Suhrkamp.

Watzlawick, P. (1975). Wesen und Formen menschlicher Beziehungen. In H.-G. Gadamer, \& P. Vogeler (Hrsg.), Neue Anthropologie (pp. 103-131). Stuttgart: Thieme.

Watzlawick, P. (1979). Kommumikation und Interaktion in psychiatrischer Sicht. In K. P. Kisker, et al., Psychiatrie der Gegenwart (pp. 599-626). Berlin: Springer.

Weeks, G. (1977). Toward a Dialectical Approach to Intervention. Human Development, 20, 277-292.

Wein, H. (1974). Ende der Philosophie? Philosophische Anthropologie und kein Ende. In J. M. Broekman, \& G. Hofer (Hrsg.), Die Wirklichkeit des Unverständlichen. Festschrift für H. Müller-Suur (88-113). Den Haag: Nijhoff.

Weitbrecht, H.-H. (1955). Kritik der Psychosomatik. Stuttgart: Thieme.

Wiehl, R. (1970). Begriffsbestimmung und Begriffsgeschichte. Zum Verhältnis von Phänomenologie, Dialektik und Hermeneutik. In Bubner et al. (pp. 167-213).

Wolff, S. (1976). Sozialpsychologische Anmerkungen zur psychiatrischen Krisenintervention. SoziologenKorrespondenz, 3, 144-215.

Wuchterl, K. (1977). Die dialektische Methode. Kritische Stimmen zur Dialektik. In Methoden der Gegenwartsphilosophie (pp. 105-161). Bern: Haupt.

Wynne, L. C. (1976). Über Qual und schöpferische Leidenschaft im Banne des „,doublebind" — Eine Neuformulierung. Familiendynamik, 1, 23-35.

Wyss, D. (1973). Beziehung und Gestalt. Göttingen: Vandenhoeck \& Rupprecht.

Wyss, D. (1976). Die anthropologisch-existentialontologische Psychologie und ihre Auswirkungen insbesondere auf die Psychiatrie und Psychotherapie. In H. Balmer, (Hrsg.), Psychologie des 20. Jahrhunderts (pp. 460569). Zürich: Kindler.

Ziller, R. C. (1977). Group dialectics: the dynamics of groups over time. Human Development, 20, 277-292. 